\title{
BMJ Open Population-based cohort study on the risk of pneumonia in patients with non-traumatic intracranial haemorrhage who use proton pump inhibitors
}

\author{
Sai-Wai Ho, ${ }^{1,2}$ Ming-Che Tsai, ${ }^{1,2}$ Ying-Hock Teng, ${ }^{1,2}$ Ying-Tung Yeh, ${ }^{3}$ \\ Yu-Hsun Wang, ${ }^{4}$ Shun-Fa Yang, ${ }^{4,5}$ Chao-Bin Yeh ${ }^{1,2}$
}

To cite: Ho S-W, Tsai M-C, Teng Y-H, et al. Populationbased cohort study on the risk of pneumonia in patients with non-traumatic intracranial haemorrhage who use proton pump inhibitors. BMJ Open 2014;4:e006710. doi:10.1136/bmjopen-2014006710

- Prepublication history for this paper is available online. To view these files please visit the journal online (http://dx.doi.org/10.1136/ bmjopen-2014-006710).

S-WH and M-CT contributed equally.

Received 24 September 2014 Revised 20 October 2014 Accepted 24 October 2014

CrossMark

For numbered affiliations see end of article.

Correspondence to

Dr Chao-Bin Yeh;

sky5ff@gmail.com

\section{ABSTRACT}

Objectives: This nationwide cohort study investigated the association between proton pump inhibitor (PPI) usage and the risk of pneumonia in patients with nontraumatic intracranial haemorrhage (ICH).

Design: Nationwide population-based cohort study. Setting: Longitudinal Health Insurance Database 2010 (LHID2010) sampled from the Taiwan National Health Insurance Research Database.

Participants: 4644 patients with non-traumatic ICH from 2010 to 2011 were identified. Patients aged $<18$ years and newly diagnosed with non-traumatic ICH complicated with pneumonia during the same admission period were excluded. A total of 2170 participants were eligible for the final analysis.

Main outcome measure: Patients using PPIs or not during the study period were tracked to identify the occurrence of any type of pneumonia.

Results: The adjusted HR of the risk of pneumonia for ICH patients who used PPIs was $1.61(95 \% \mathrm{Cl} 1.32$ to $1.97, p<0.001)$. The risk of pneumonia was positively associated with the administration of PPIs. We observed a greater risk of pneumonia in patients who used PPIs than in those who did not. Moreover, we observed that the risk of pneumonia in patients who used PPIs was 2.60 and $2.04(95 \% \mathrm{Cl} 2.01$ to 3.38 , $\mathrm{p}<0.001 ; 95 \% \mathrm{Cl} 1.34$ to $3.10, \mathrm{p}<0.001)$ greater than that in patients who did not use PPIs when the defined daily dose was $<30$ and $30-60$, respectively.

Conclusions: The results of this study indicate that the use of PPIs in patients with non-traumatic ICH is associated with an increased risk of pneumonia, and the severity of this risk depends on the defined daily dose. Physicians should exercise caution when prescribing PPIs for patients with non-traumatic $\mathrm{ICH}$.

\section{INTRODUCTION}

Pneumonia is an inflammatory condition of the lung that involves the pulmonary parenchyma and develops through proliferation of microbial pathogens at the alveolar level of the respiratory tract and the response of the

\section{Strengths and limitations of this study}

- This is the first large-scale population-based cohort study to evaluate the relationship between the use of proton pump inhibitors (PPIs) and the risk of pneumonia in patients with non-traumatic intracranial haemorrhage. Moreover, the strong evidence base can be used to investigate the causal relationship.

- The study from the National Health Insurance database is representative of the study sample, and the study population is large enough for stratified analysis of the different disease-severity groups.

- Since our study comes from National Health Insurance claims data, its major limitation is lack of clinical information. There are no laboratory data and no disease severity measures such as Glasgow Coma Scale, Modified Rankin Scale or National Institutes of Health Stroke Scale scores for the studied patients.

- Other study limitations include the unavailability of potential lifestyle factors and patients' medication compliance, which could potentially confound the relationship between the use of PPIs and risk of pneumonia.

host. ${ }^{1-4}$ Moreover, it is an infectious disease that is associated with considerable morbidity and mortality, and is the most common fatal infection acquired in hospitals, causing the deaths of 3.2 million people worldwide in 2011. In Taiwan, pneumonia was the fourth leading cause of death in 2012 according to the statistics of the Ministry of Health and Welfare. ${ }^{5}{ }^{6}$ Stroke patients commonly experience cardiac complications, pneumonia, thromboembolism, gastrointestinal bleeding and urinary tract infection, which require prompt diagnosis and management. It has been shown that, of these complications, pneumonia plays the most vital role in the inter-relationship. ${ }^{7} 8$ Therefore preventing 
pneumonia is vital to reducing morbidity and mortality, especially in stroke patients. Most stroke-related pneumonia is believed to result from aspiration. Gastrointestinal symptoms often occur in patients with non-traumatic intracranial haemorrhage (ICH), and proton pump inhibitors (PPIs) are therapeutically indicated for gastrointestinal disorders involving excessive acid production. ${ }^{9}$ However, it has been reported that using acidsuppressive medication such as a PPI increases the risk of pneumonia in older people. ${ }^{10-12}$ Several studies have confirmed that using prophylactic PPIs during an acute non-traumatic ICH stroke can increase the risk of hospital-acquired pneumonia through acute and irreversible gastric acid suppression. ${ }^{13}$ However, the relationship between short-term and long-term PPI use and pneumonia in patients with non-traumatic ICH has not been determined. The purpose of this study was to investigate the association between PPI use and pneumonia in patients with non-traumatic ICH using a nationwidebased dataset.

\section{METHODS AND MATERIALS \\ Data sources}

A retrospective cohort population-based study was conducted using registration and claims datasets from 2010 to 2011 obtained from the Longitudinal Health Insurance Database 2010 (LHID2010), a subset of the National Health Insurance Research Database (NHIRD), which is managed by the Taiwanese National Health Research Institutes (NHRI). The LHID2010 contains all ambulatory and inpatient claims data on one million beneficiaries who were randomly sampled from the 2010 registry for beneficiaries of the NHIRD, and we used these data to examine the association between PPI use and pneumonia in patients with non-traumatic ICH with up to 2 years of follow-up (figure 1). We used age- and sex-matched control for these two cofounding factors, so that our study could use propensity score matching for rigorous statistical matching, which can effectively identify the characteristics of similar groups. However, some information may be lost if over-matching because, again, the matched factors cannot be used to analyse between the disease and other factors. These databases have previously been used in numerous medical studies and have proven to be of high quality. ${ }^{14-16}$ This study was approved by the Institutional Review Board of Chung Shan Medical University Hospital (CSMU No 14056). Because all personal data in the secondary files were deidentified before they were analysed, the review board waived the requirement to obtain written informed consent from the patients.

\section{Study sample and setting}

Patients aged $>18$ years who had non-traumatic ICH were included in the study. We defined non-traumatic ICH according to the International Classification of Diseases, Ninth Revision, Clinical Modification
(ICD-9-CM) codes 430, 431 and 432.xx. Pneumonia was defined according to ICD-9-CM codes 481, 482.xx, 483.xx, 485 and 486 (table 1). We analysed data on all patients with non-traumatic ICH from 1 January 2010 to 31 December 2010. The average follow-up was 1.05 years. We first excluded patients aged under 18 years and then those newly diagnosed with nontraumatic ICH complicated with pneumonia during the same admission period, because the primary objective of this study was to observe whether patients with nontraumatic ICH using PPIs developed pneumonia. Patients who had a history of pneumonia in the year before PPI treatment was initiated were also excluded. The study cohort comprised 3982 patients with nontraumatic ICH. These patients were divided into PPI and non-PPI groups. Figure 1 shows the study framework. Five PPI medications are available in Taiwan, namely omeprazole, pantoprazole, lansoprazole, esomeprazole and rabeprazole. We excluded the intravenous form of PPI because it is usually administered under acute conditions. To measure drug use, we used the defined daily dose (DDD), which was recommended by the WHO. ${ }^{17}$ Cumulative DDDs were estimated as the sum of the dispensed DDD of any PPI and the final use during the study observation time period.

In addition, we collected information on age, sex, monthly income, urbanisation and comorbidities. Comorbidities were represented using the Charlson Comorbidity Index (CCI) as described in previous studies. ${ }^{18-20}$ The comorbidities considered in the CCI score were myocardial infarction (ICD-9-CM 410-410.9, 412), congestive heart failure (ICD-9-CM 428-428.9), peripheral vascular disease (ICD-9-CM 443.9, 441, 441.9, 785.4, V43.4), cerebrovascular disease (ICD-9-CM 430-437, 438), dementia (ICD-9-CM 290-290.9), chronic pulmonary disease (ICD-9-CM 490-496, 500-505, 506.4), rheumatologic disease (ICD-9-CM 710, 710.1, 710.4, 714-714.2, 714.81, 725), peptic ulcer disease (ICD-9-CM 531-534.9, 531.4-531.7, 532.4-532.7, 533.4-533.7, 534.4-534.7), mild liver disease (ICD-9-CM 571.2, 571.5, 571.6, 571.4-571.49), diabetes (ICD-9-CM 250-250.3, 250.7), diabetes with chronic complications (ICD-9-CM 250.4-250.6), hemiplegia or paraplegia (ICD-9-CM 344.1, 342-342.9), renal disease (ICD-9-CM 582-582.9, 583-583.7, 585, 586, 588-588.9), malignancies including leukaemia and lymphoma (ICD-9-CM 140-172.9, 174-195.8, 200-208.9), moderate and severe liver disease (ICD-9-CM 572.2-572.8, 456.0-456.21), metastatic solid tumours (ICD-9-CM 196-199.1), and acquired immune deficiency syndrome (ICD-9-CM 042.0-044.9).

\section{Statistical analysis}

Categorical variables are presented as counts and percentages and were compared using the $\chi^{2}$ test where appropriate. Continuous data are presented as mean $\pm \mathrm{SD}$ and were compared using the independent $t$ test. Cox proportional hazard model analysis was performed to estimate the HR of pneumonia in the PPI group and the non-PPI 


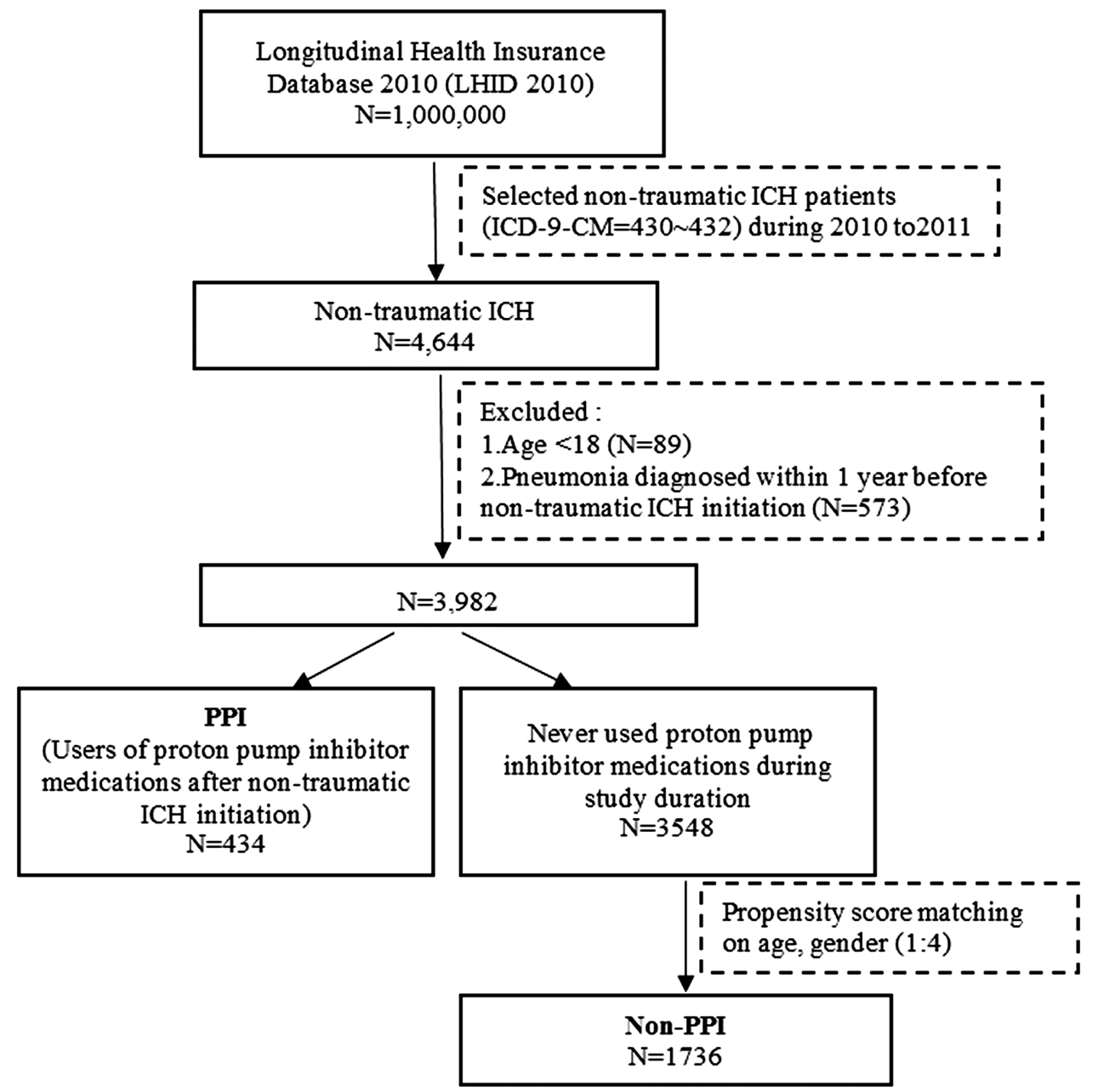

Figure 1 Flow chart for selecting patients with non-traumatic intracranial haemorrhage (ICH).

group. In addition, we adjusted for potential confounding factors that may have influenced calculation of the risk of pneumonia development, namely age, sex, CCI, monthly income, and urbanisation. Statistical analysis was performed using SPSS V.18.0. A p value $<0.05$ was considered to indicate significance. Development of pneumonia was assessed using Kaplan-Meier analysis, in which significance was based on the log rank test.

\section{RESULTS}

We identified 4644 patients with non-traumatic ICH over the 1-year study period. After patients diagnosed at $<18$ years of age $(\mathrm{N}=89)$ and those who had a history of pneumonia within the preceding year $(\mathrm{N}=573)$ had been excluded, the sample consisted of 3982 patients (434 in the PPI group and 3548 in the non-PPI group). The patient age ranged from 18 to 100 years, and the mean \pm SD ages in the PPI group and non-PPI group were $66.43 \pm 14.90$ years and $65.52 \pm 15.51$ years, respectively. The patients who were diagnosed with ICH were predominantly male $(64.52 \%)$. After the patients had been matched, the CCIs of $21.95 \%, 51.9 \%$ and $26.15 \%$ of the patients in the PPI group were 0,1 and $\geq 2$, respectively. Table 2 shows demographic, comorbidity and clinical data on the patients with non-traumatic ICH who did and did not use PPIs.

The crude HR results indicate that the pneumonia risk of patients who used PPIs was 1.70 times greater than that of the patients in the non-PPI group (95\% CI 1.40 to 2.08). Patients aged over 65 years were associated with a higher probability of developing pneumonia than were those aged 18-39 years (adjusted $\mathrm{HR}=2.62$, 95\% CI 1.49 to 4.59 ). Moreover, men exhibited a significantly higher probability of developing pneumonia than women (adjusted $\mathrm{HR}=1.36$, 95\% CI 1.12 to 1.66). Furthermore, a CCI $\geq 1$ was associated with a significantly higher probability of developing pneumonia (CCI $=1$, Adjusted $\mathrm{HR}=1.62$, 95\% CI 1.15 to 2.27; CCI $\geq 2$, Adjusted HR=1.58, 95\% CI 1.11 to 2.27 ), as illustrated in table 3. A DDD of PPI $<60$ was associated with a significantly increased risk of pneumonia compared with a DDD of 0 (non-PPI group). However, no significant difference in the risk of pneumonia was observed between a DDD of PPI $>60$ and a DDD of 0 (non-PPI group), as illustrated in table 4 . Thus, the risk of pneumonia varied according to the cumulative dose of PPI.

Figure 2 shows Kaplan-Meier curves of the occurrence of pneumonia in patients with non-traumatic ICH in the PPI 
Table 1 ICD-9-CM (International Classification of Diseases, Ninth Revision, Clinical Modification) codes used to identify disease categories

\section{ICD-9-CM

code Diagnosis

\section{Pneumonia}

$481 \quad$ Pneumococcal pneumonia

$482 \quad$ Other bacterial pneumonia

$482.0 \quad$ Pneumonia due to Klebsiella pneumoniae

$482.1 \quad$ Pneumonia due to Pseudomonas

482.2 Pneumonia due to Haemophilus influenzae

482.3 Pneumonia due to Streptococcus

482.30 Pneumonia due to Streptococcus, unspecified

482.31 Pneumonia due to Streptococcus, Group A

482.32 Pneumonia due to Streptococcus, Group B

482.39 Pneumonia due to other Streptococcus

$482.4 \quad$ Pneumonia due to Staphylococcus

482.40 Pneumonia due to Staphylococcus, unspecified

$482.41 \quad$ Pneumonia due to Staphylococcus aureus

482.49 Pneumonia due to other Staphylococcus

482.8 Pneumonia due to other specified bacteria

482.81 Pneumonia due to Anaerobes

482.82 Pneumonia due to Escherichia coli

482.83 Pneumonia due to other Gram-negative bacteria

$482.84 \quad$ Legionnaires' disease

$482.89 \quad$ Other specified bacteria

$482.9 \quad$ Bacterial pneumonia, unspecified

483 Pneumonia due to other specified organism

483.0 Pneumonia due to Mycoplasma pneumoniae

483.1 Pneumonia due to Chlamydia

483.8 Pneumonia due to other specified organism

$485 \quad$ Bronchopneumonia, organism unspecified

$486 \quad$ Pneumonia, organism unspecified

Non-traumatic $\mathrm{ICH}$

$430 \quad$ Subarachnoid haemorrhage

$431 \quad$ Intracerebral haemorrhage

$432 \quad$ Other and unspecified intracerebral

haemorrhage

$432.0 \quad$ Non-traumatic extradural haemorrhage

$432.1 \quad$ Subdural haemorrhage

$432.9 \quad$ Unspecified ICH

$\mathrm{ICH}$, intracranial haemorrhage.

and non-PPI groups with various CCI scores. Figures 2A-C show CCI scores of 0,1 and $\geq 2$, and figure 2D shows the overall CCI. The overall CCI was associated with a significant increase in the cumulative incidence of pneumonia in the PPI group compared with the non-PPI group.

\section{DISCUSSION}

According to our thorough review of relevant research, this study is the first to explore the association between PPI and pneumonia in patients with non-traumatic stroke using a nationwide dataset. The strength of this cohort study is the use of the LHID2010 nationwide database. In Taiwan, the National Health Insurance system has covered the medical service use of nearly $98 \%$ of the Taiwanese population since 1995; thus, the data accurately represent the medical situation in Taiwan. The incidence of pneumonia in this study group was $11.8 \%$, which is similar to that reported by a previous cohort study conducted in the UK $(13.8 \%){ }^{21}$

Non-traumatic ICH pneumonia is associated with an adverse outcome, a prolonged hospital stay, and increased health costs. In this large population-based study, we observed that PPI administration was strongly associated with pneumonia. PPI administration is the leading treatment for acid-related gastrointestinal disorders. Gastro-oesophageal reflux and gastric ulcer bleeding are common complications of stroke that can be managed using PPIs. ${ }^{22}$ However, when gastric acid secretion is suppressed, gastric bacterial overgrowth can contribute to aspiration pneumonia. ${ }^{23}$ Several previous studies have reported that PPI therapy is associated with an increased risk of community-acquired pneumonia. ${ }^{11} 12{ }^{24}$ DDD, the cumulative dose of PPI drug, is divided into five groups. The 'never used PPI' population numbered 1736 , and the cumulative dose in this group was none; other groups were formed according to the cumulative dose of PPI drug divided into $<30$, 30-60, 61-90 and >90 DDD. However, our results reveal that an association can be established during short-term PPI therapy $(<30$ and $30-60$ DDD, HR $2.60(95 \%$ CI 2.01 to 3.38 ), $\mathrm{p}<0.001$ and HR 2.04 (95\% CI 1.34 to $3.10), \mathrm{p}<0.001$, respectively). We observed that long-term PPI use does not increase the risk of communityacquired pneumonia. This result is similar to that reported by Sarkar et $a l,{ }^{25}$ who observed that PPI therapy initiated within the preceding 30 days was associated with an increased risk of community-acquired pneumonia, whereas long-term current use was not. Ran et $a l^{13}$ observed that using PPI as a prophylactic treatment for stress-related mucosal damage was associated with a higher occurrence of nosocomial pneumonia in the ICH population. In our study, we excluded patients with nosocomial pneumonia during the acute ICH phase to eliminate potential confounding factors such as intubation and mechanical-ventilation-associated pneumonia.

The CCI is a scoring system that is commonly used to measure patients' comorbid conditions. Although CCI was first really get inside comorbidity weighted values from survival analysis, in most healthcare research it is also used as disease severity adjustment. The Index encompasses 19 medical conditions that are weighted $1-6$, with total scores ranging from 0 to 37 . It is widely used to predict operation complications ${ }^{26}$ and mortality caused by pneumonia and cancer, ${ }^{27-29}$ and to control for confounding factors in epidemiological studies using claims data. ${ }^{18}$ A previous study revealed that a CCI $\geq 3$ is a risk factor for developing hospital-acquired pneumonia. ${ }^{30}$ In this study, we confirmed that a high CCI score is associated with a high risk of pneumonia. A higher 
Table 2 Baseline demographic and clinical data on patients with non-traumatic intracranial haemorrhage who did or did not use proton pump inhibitors (PPIs) in Taiwan in 2010 ( $N=3982)$ as well as the matched cohort $(\mathrm{N}=2170)$

\begin{tabular}{|c|c|c|c|c|c|c|c|c|c|c|}
\hline \multirow[b]{3}{*}{ Characteristic } & \multicolumn{4}{|c|}{ Unmatching ${ }^{*}$} & \multirow[b]{3}{*}{ p Value } & \multicolumn{4}{|c|}{ Matching* } & \multirow[b]{3}{*}{ p Value } \\
\hline & \multicolumn{2}{|c|}{ PPI (N=434) } & \multicolumn{2}{|c|}{$\begin{array}{l}\text { Non-PPI } \\
(\mathrm{N}=3548)\end{array}$} & & \multicolumn{2}{|c|}{ PPI (N=434) } & \multicolumn{2}{|c|}{$\begin{array}{l}\text { Non-PPI } \\
(\mathrm{N}=1736)\end{array}$} & \\
\hline & $\mathrm{n}$ & Per cent & n & Per cent & & $\bar{n}$ & Per cent & $\mathrm{n}$ & Per cent & \\
\hline Gender & & & & & 0.244 & & & & & \multirow[t]{3}{*}{1.000} \\
\hline Female & 154 & 35.48 & 1361 & 38.36 & & 154 & 35.48 & 616 & 35.48 & \\
\hline Male & 280 & 64.52 & 2187 & 61.64 & & 280 & 64.52 & 1120 & 64.52 & \\
\hline Age, years & & & & & $<0.001$ & & & & & 1.000 \\
\hline $18-39$ & 26 & 5.99 & 402 & 11.33 & & 26 & 5.99 & 104 & 5.99 & \\
\hline $40-64$ & 158 & 36.41 & 1640 & 46.22 & & 158 & 36.41 & 632 & 36.41 & \\
\hline$\geq 65$ & 250 & 57.60 & 1506 & 42.45 & & 250 & 57.60 & 1000 & 57.6 & \\
\hline Mean \pm SD & \multicolumn{2}{|c|}{$66.43 \pm 14.90$} & \multicolumn{2}{|c|}{$60.89 \pm 16.58$} & $<0.001$ & \multicolumn{2}{|c|}{$66.43 \pm 14.90$} & \multicolumn{2}{|c|}{$65.52 \pm 15.51$} & 0.195 \\
\hline Track duration & \multicolumn{2}{|c|}{$1.05 \pm 0.68$} & \multicolumn{2}{|c|}{$1.08 \pm 0.72$} & 0.463 & \multicolumn{2}{|c|}{$1.05 \pm 0.68$} & \multicolumn{2}{|c|}{$1.05 \pm 0.73$} & 0.855 \\
\hline Monthly income & & & & & 0.864 & & & & & 0.776 \\
\hline$\leq \mathrm{NT} \$ 19200$ & 256 & 58.99 & 2108 & 59.41 & & 256 & 58.99 & 1037 & 59.74 & \\
\hline$>$ NT\$19200 & 178 & 41.01 & 1440 & 40.59 & & 178 & 41.01 & 699 & 40.26 & \\
\hline Urbanisation & & & & & 0.074 & & & & & 0.278 \\
\hline Urban & 241 & 55.53 & 1937 & 54.59 & & 241 & 55.53 & 937 & 53.97 & \\
\hline Suburban & 125 & 28.80 & 1169 & 32.95 & & 125 & 28.80 & 562 & 32.37 & \\
\hline Rural & 68 & 15.67 & 442 & 12.46 & & 68 & 15.67 & 237 & 13.65 & \\
\hline $\mathrm{CCl}$ & & & & & $<0.001$ & & & & & $<0.001$ \\
\hline 0 & 28 & 6.45 & 932 & 26.27 & & 28 & 6.45 & 381 & 21.95 & \\
\hline 1 & 227 & 52.30 & 1751 & 49.35 & & 227 & 52.30 & 901 & 51.9 & \\
\hline$\geq 2$ & 179 & 41.24 & 865 & 24.38 & & 179 & 41.24 & 454 & 26.15 & \\
\hline
\end{tabular}

Table 3 Cox proportional HR of pneumonia between patients with non-traumatic intracranial haemorrhage who used proton pump inhibitors (PPIs) $(\mathrm{N}=434)$ and those who did not use PPIs $(\mathrm{N}=1736)$

\begin{tabular}{|c|c|c|c|c|c|c|c|c|}
\hline & \multirow[b]{2}{*}{$\begin{array}{l}\text { Patients } \\
\text { (N) }\end{array}$} & \multirow[b]{2}{*}{$\begin{array}{l}\text { Pneumonia } \\
\text { events (N) }\end{array}$} & \multirow[b]{2}{*}{$\begin{array}{l}\text { Crude } \\
\text { HR }\end{array}$} & \multicolumn{2}{|l|}{$95 \% \mathrm{Cl}$} & \multirow[b]{2}{*}{$\begin{array}{l}\text { Adjusted } \\
\text { HR }\end{array}$} & \multicolumn{2}{|l|}{$95 \% \mathrm{Cl}$} \\
\hline & & & & Lower & Upper & & Lower & Upper \\
\hline \multicolumn{9}{|l|}{$\overline{\mathrm{PPI}}$} \\
\hline No & 1736 & 326 & 1 & & & 1 & & \\
\hline Yes & 434 & 142 & $1.70^{\star *}$ & 1.40 & 2.08 & $1.61^{\star *}$ & 1.32 & 1.97 \\
\hline \multicolumn{9}{|l|}{ Gender } \\
\hline Female & 770 & 151 & 1 & & & 1 & & \\
\hline Male & 1400 & 317 & 1.11 & 0.92 & 1.35 & $1.36^{\star \star}$ & 1.12 & 1.66 \\
\hline \multicolumn{9}{|l|}{ Age, years } \\
\hline $18-39$ & 130 & 13 & 1 & & & 1 & & \\
\hline $40-64$ & 790 & 112 & 1.24 & 0.70 & 2.20 & 1.22 & 0.69 & 2.17 \\
\hline$\geq 65$ & 1250 & 343 & $2.73^{\star *}$ & 1.57 & 4.76 & $2.62^{\star \star}$ & 1.49 & 4.59 \\
\hline \multicolumn{9}{|l|}{ Monthly income } \\
\hline$\leq \mathrm{NT} \$ 19200$ & 1293 & 309 & 1 & & & 1 & & \\
\hline >NT\$19200 & 877 & 159 & $0.76^{\star \star}$ & 0.63 & 0.92 & $0.81^{*}$ & 0.66 & 0.99 \\
\hline \multicolumn{9}{|l|}{ Urbanisation } \\
\hline Urban & 1178 & 250 & 1 & & & 1 & & \\
\hline Suburban & 687 & 141 & 0.98 & 0.79 & 1.20 & 1.02 & 0.82 & 1.25 \\
\hline Rural & 305 & 77 & 1.25 & 0.96 & 1.61 & 1.22 & 0.94 & 1.59 \\
\hline \multicolumn{9}{|l|}{$\mathrm{CCl}$} \\
\hline 0 & 409 & 40 & 1 & & & 1 & & \\
\hline 1 & 1128 & 273 & $2.23^{\star \star}$ & 1.60 & 3.11 & $1.62^{\star \star}$ & 1.15 & 2.27 \\
\hline$\geq 2$ & 633 & 155 & $2.30^{\star \star}$ & 1.62 & 3.25 & $1.58^{*}$ & 1.11 & 2.27 \\
\hline
\end{tabular}


Table 4 Dose effect analysis of patients with non-traumatic intracranial haemorrhage who received proton pump inhibitor (PPI) therapy attributable to pneumonia

\begin{tabular}{|c|c|c|c|c|c|c|c|c|}
\hline \multirow[b]{2}{*}{$\begin{array}{l}\text { PPI } \\
\text { exposure }\end{array}$} & \multirow[b]{2}{*}{$\begin{array}{l}\text { Patients } \\
\text { (N) }\end{array}$} & \multirow[b]{2}{*}{$\begin{array}{l}\text { Pneumonia } \\
\text { events (N) }\end{array}$} & \multirow[b]{2}{*}{$\begin{array}{l}\text { Crude } \\
\text { HR }\end{array}$} & \multicolumn{2}{|l|}{$95 \% \mathrm{Cl}$} & \multirow[b]{2}{*}{$\begin{array}{l}\text { Adjusted } \\
\text { HR† }\end{array}$} & \multicolumn{2}{|l|}{$95 \% \mathrm{Cl}$} \\
\hline & & & & Lower & Upper & & Lower & Upper \\
\hline None & 1736 & 326 & 1 & & & 1 & & \\
\hline$<30$ DDD & 172 & 70 & $2.62^{\star \star}$ & 2.02 & 3.39 & $2.60^{\star \star}$ & 2.01 & 3.38 \\
\hline 30-60 DDD & 70 & 24 & $2.21^{\star \star}$ & 1.46 & 3.34 & $2.04^{\star \star}$ & 1.34 & 3.10 \\
\hline 61-90 DDD & 34 & 7 & 0.91 & 0.43 & 1.92 & 0.80 & 0.38 & 1.68 \\
\hline >90 DDD & 158 & 41 & 1.08 & 0.78 & 1.50 & 1.00 & 0.72 & 1.39 \\
\hline
\end{tabular}

CCI score represents greater numbers of comorbidities and neurological consequences and a greater degree of immunocompromise. All of these conditions are risk factors for pneumonia, as described in previous literature. ${ }^{31-33}$

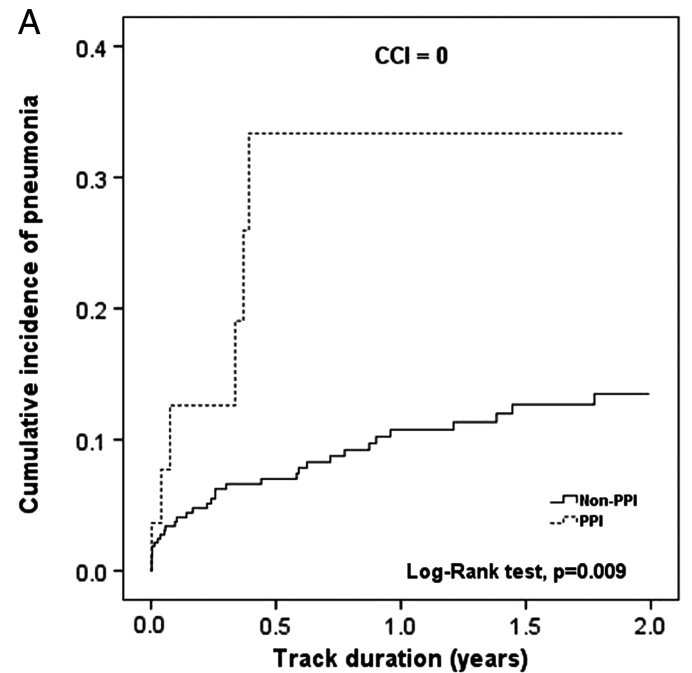

C

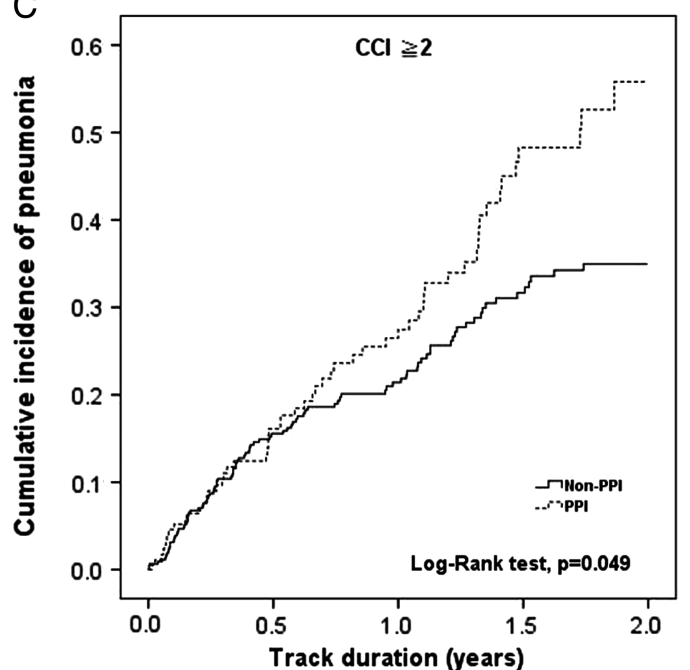

Another interesting finding is that low-income patients and those who live in rural areas exhibited an increased risk of developing pneumonia. The economy of Taiwan, a developed country, has been classified as advanced by the International Monetary Fund. Taiwan has 123
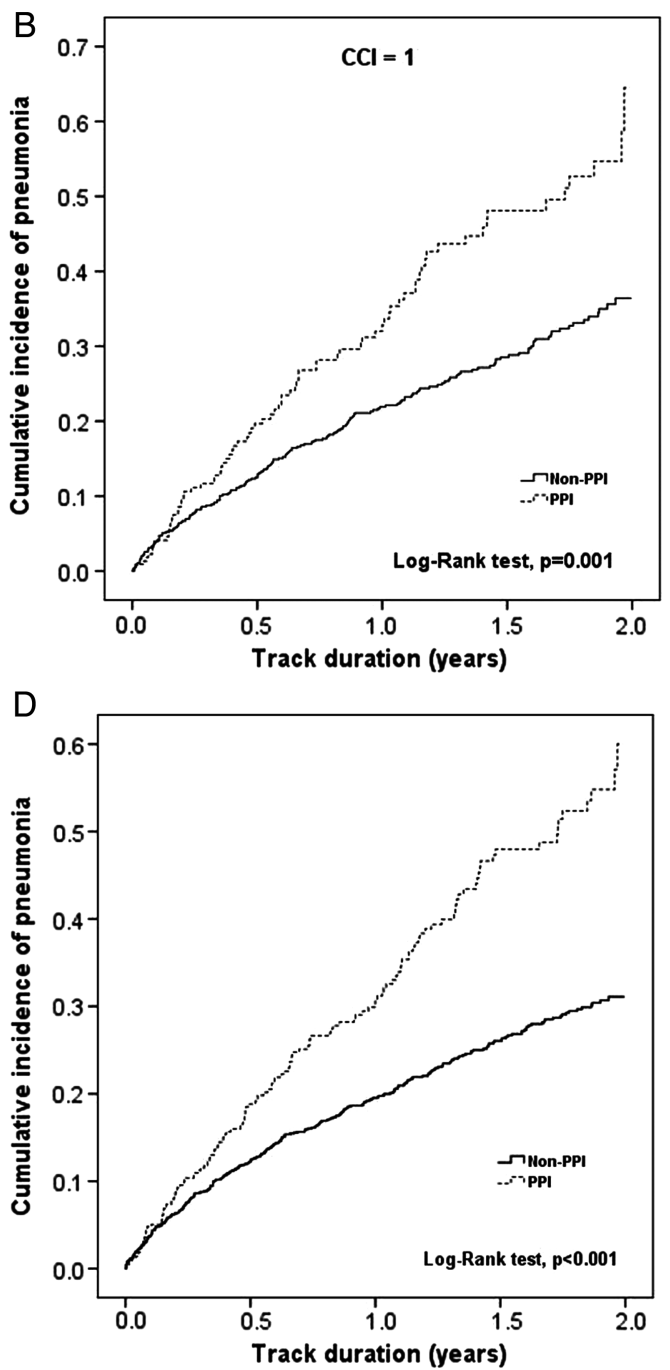

Figure 2 Kaplan-Meier curves of the occurrence of pneumonia in patients with non-traumatic intracranial haemorrhage who used proton pump inhibitors (PPIs) and those who did not use PPIs. (A) Charlson Comorbidity Index (CCI)=0; $(\mathrm{B}) \mathrm{CCl}=1$; (C) $\mathrm{CCl} \geq 2$; (D) overall CCl. 
academic medical centres and 437 local community hospitals that service 23 million Taiwanese people. Healthcare services in Taiwan are managed by the Bureau of National Health Insurance, which reduces co-payments for low-income, disabled and elderly patients. Thus, seeking medical care in Taiwan is convenient and inexpensive. We attribute the low risk of pneumonia among low-income patients and those who live in rural areas to these characteristics of the Taiwanese healthcare system.

This study has some limitations. First, no clinical information was available on the Glasgow Coma Scale or Modified Rankin Scale scores of the stroke patients. Moreover, the neurological condition of the patients (such as dysphagia) was unclear. A previous study reported that dysphagia treated by feeding through a nasogastric tube is a predictor of the development of pneumonia in patients with ICH. ${ }^{34}$ In this study, we used the CCI to partially overcome this limitation. Second, the database does not include information on over-the-counter PPI use or treatment compliance. Thus, the effect of PPI use may have been underestimated. Third, several potential lifestyle confounders that are associated with pneumonia, such as smoking, alcohol misuse, being underweight, having regular contact with children, and poor dental hygiene, were not included in the database. Therefore, further research on the relationship between PPIs and pneumonia in patients with non-traumatic ICH is required.

\section{CONCLUSION}

Our study reveals that the use of PPIs in patients with nontraumatic ICH is associated with an increased risk of pneumonia, and the severity of this risk varies according to the DDD. Physicians should exercise caution when prescribing PPIs to patients with non-traumatic ICH.

\section{Author affiliations \\ ${ }^{1}$ Department of Emergency Medicine, School of Medicine, Chung Shan Medical University, Taichung, Taiwan \\ 2Department of Emergency Medicine, Chung Shan Medical University Hospital, Taichung, Taiwan \\ ${ }^{3}$ School of Dentistry, Chung Shan Medical University, Taichung, Taiwan ${ }^{4}$ Department of Medical Research, Chung Shan Medical University Hospital, Taichung, Taiwan \\ ${ }^{5}$ Institute of Medicine, Chung Shan Medical University, Taichung, Taiwan}

Acknowledgements This study is based in part on data from the National Health Insurance Research Database provided by the National Health Insurance Administration, Ministry of Health and Welfare and managed by National Health Research Institutes (registered number: NHIRD-102-158). The interpretation and conclusions contained herein do not represent those of the National Health Insurance Administration, Ministry of Health and Welfare or National Health Research Institutes.

Contributors S-WH and C-BY conceived and designed the experiments. Y-HT, Y-TY and Y-HW analysed the data. S-FY and C-BY wrote the paper, and all authors read and approved the final version of the manuscript.

Funding This research received no specific grant from any funding agency in the public, commercial or not-for-profit sectors.

Competing interests None.
Ethics approval CSMU No 14056.

Provenance and peer review Not commissioned; externally peer reviewed.

Data sharing statement No additional data are available.

Open Access This is an Open Access article distributed in accordance with the Creative Commons Attribution Non Commercial (CC BY-NC 4.0) license, which permits others to distribute, remix, adapt, build upon this work noncommercially, and license their derivative works on different terms, provided the original work is properly cited and the use is non-commercial. See: http:// creativecommons.org/licenses/by-nc/4.0/

\section{REFERENCES}

1. Chiang TY, Yu YL, Lin CW, et al. The circulating level of MMP-9 and its ratio to TIMP-1 as a predictor of severity in patients with community-acquired pneumonia. Clin Chim Acta 2013;424:261-6.

2. Ko CP, Yu YL, Hsiao PC, et al. Plasma levels of soluble Axl correlate with severity of community-acquired pneumonia. $\mathrm{Mol} \mathrm{Med}$ Rep 2014;9:1400-4

3. Chiang TY, Tsao SM, Yeh CB, et al. Matrix metalloproteinases in pneumonia. Clin Chim Acta 2014;433C:272-7.

4. Wang HL, Hsiao PC, Tsai HT, et al. Usefulness of plasma YKL-40 in management of community-acquired pneumonia severity in patients. Int J Mol Sci 2013;14:22817-25.

5. Ramirez JA, Anzueto AR. Changing needs of community-acquired pneumonia. J Antimicrob Chemother 2011;66:iii3-9.

6. Department of Statistics of Ministry of Health and Welfare in Taiwan. Causes of death in Taiwan. Taipei: Ministry of Health and Welfare in Taiwan, 2012.

7. Kumar S, Selim MH, Caplan LR. Medical complications after stroke. Lancet Neurol 2010;9:105-18.

8. Ji R, Wang $\mathrm{D}$, Shen $\mathrm{H}$, et al. Interrelationship among common medical complications after acute stroke: pneumonia plays an important role. Stroke 2013;44:3436-44.

9. Yang TC, Li JG, Shi HM, et al. Gastrointestinal bleeding after intracerebral hemorrhage: a retrospective review of 808 cases. $A m ~ J$ Med Sci 2013;346:279-82.

10. Dublin $\mathrm{S}$, Walker RL, Jackson $\mathrm{ML}$, et al. Use of proton pump inhibitors and $\mathrm{H} 2$ blockers and risk of pneumonia in older adults: a population-based case-control study. Pharmacoepidemiol Drug Saf 2010;19:792-802.

11. Laheij RJ, Sturkenboom MC, Hassing RJ, et al. Risk of community-acquired pneumonia and use of gastric acid-suppressive drugs. JAMA 2004;292:1955-60.

12. Eurich DT, Sadowski CA, Simpson $\mathrm{SH}$, et al. Recurrent community-acquired pneumonia in patients starting acid-suppressing drugs. Am J Med 2010;123:47-53.

13. Ran L, Khatibi NH, Qin X, et al. Proton pump inhibitor prophylaxis increases the risk of nosocomial pneumonia in patients with an intracerebral hemorrhagic stroke. Acta Neurochir Suppl 2011;111:435-9.

14. Chang LY, Chang IS, Lu CY, et al. Epidemiologic features of Kawasaki disease in Taiwan, 1996-2002. Pediatrics 2004;114:e678-82.

15. Lin $\mathrm{HC}$, Xirasagar $\mathrm{S}$, Chen $\mathrm{CH}$, et al. Physician's case volume of intensive care unit pneumonia admissions and in-hospital mortality. Am J Respir Crit Care Med 2008;177:989-94.

16. Lee HC, Lin HC, Tsai SY. Severely depressed young patients have over five times increased risk for stroke: a 5-year follow-up study. Biol Psychiatry 2008;64:912-15.

17. WHO Collaborating Center for Drugs Statistics Methodology. ATC Index With DDDs 2003. Oslo: WHO, 2003.

18. Schneeweiss S, Seeger JD, Maclure M, et al. Performance of comorbidity scores to control for confounding in epidemiologic studies using claims data. Am J Epidemiol 2001;154:854-64.

19. Charlson ME, Pompei P, Ales KL, et al. A new method of classifying prognostic comorbidity in longitudinal studies: development and validation. J Chronic Dis 1987;40:373-83.

20. Deyo RA, Cherkin DC, Ciol MA. Adapting a clinical comorbidity index for use with ICD-9-CM administrative databases. J Clin Epidemiol 1992;45:613-19.

21. Taylor JK, Fleming GB, Singanayagam A, et al. Risk factors for aspiration in community-acquired pneumonia: analysis of a hospitalized UK cohort. Am J Med 2013;126:995-1001.

22. Satou $Y$, Oguro $H$, Murakami $Y$, et al. Gastroesophageal reflux during enteral feeding in stroke patients: a 24-hour esophageal pH-monitoring study. J Stroke Cerebrovasc Dis 2013;22:185-9.

23. Theisen J, Nehra D, Citron D, et al. Suppression of gastric acid secretion in patients with gastroesophageal reflux disease results in 
gastric bacterial overgrowth and deconjugation of bile acids. J Gastrointest Surg 2000;4:50-4.

24. Eurich DT, Sadowski CA, Simpson SH, et al. Recurrent community-acquired pneumonia in patients starting acid-suppressing drugs. Am J Med 2010;123:47-53.

25. Sarkar M, Hennessy S, Yang YX. Proton-pump inhibitor use and the risk for community-acquired pneumonia. Ann Intern Med 2008;149:391-8.

26. Whitmore RG, Stephen JH, Vernick C, et al. ASA grade and Charlson Comorbidity Index of spinal surgery patients: correlation with complications and societal costs. Spine J 2014;14:31-8.

27. Sogaard OS, Lohse N, Gerstoft J, et al. Mortality after hospitalization for pneumonia among individuals with HIV, 1995-2008: a Danish cohort study. PLOS ONE 2009;4:e7022.

28. Tetsche MS, Dethlefsen C, Pedersen L, et al. The impact of comorbidity and stage on ovarian cancer mortality: a nationwide Danish cohort study. BMC Cancer 2008;8:31.
29. Noer MC, Sperling C, Christensen IJ, et al. Comorbidity is an independent prognostic factor in women with uterine corpus cancer: a nationwide cohort study. Acta Obstet Gynecol Scand 2014:93:325-34.

30. Sopena N, Heras E, Casas I, et al. Risk factors for hospital-acquired pneumonia outside the intensive care unit: a case-control study. Am J Infect Control 2014:42:38-42.

31. Koivula I, Sten M, Makela PH. Risk factors for pneumonia in the elderly. Am J Med 1994;96:313-20.

32. Mannino DM, Davis KJ, Kiri VA. Chronic obstructive pulmonary disease and hospitalizations for pneumonia in a US cohort. Respir Med 2009;103:224-9.

33. Polverino E, Torres Marti A. Community-acquired pneumonia. Minerva Anestesiol 2011;77:196-211.

34. Alsumrain M, Melillo N, Debari VA, et al. Predictors and outcomes of pneumonia in patients with spontaneous intracerebral hemorrhage. $\mathrm{J}$ Intensive Care Med 2013;28:118-23. 